\title{
BATHYMETRIC EXTRACTION USING WORLDVIEW-2 HIGH RESOLUTION IMAGES
}

\author{
M. Deidda ${ }^{a}$, G. Sanna ${ }^{a}$ \\ ${ }^{a}$ DICAAR, Dept. of Civil and Environmental Engineering and Architecture. - University of Cagliari, 09123 Cagliari, \\ Italy - (mdeidda, topoca)@unica.it
}

\section{Commission VIII, WG VIII/4}

KEY WORDS: Bathymetry, Underwater, Satellite, WorldView2, High resolution, Imagery, Stereoscopic, Accuracy

\begin{abstract}
:
The fundamental principle underlying the methods used to extract bathymetric information from remote-sensed imagery is that different wavelengths of the solar light penetrate the water body to different depths. In order to extract bathymetric values from multispectral satellite imagery we implemented the Jupp method (Jupp, 1988), in IDL language and integrated it in the ENVI menu structure. In this experiment we apply this method to two images of the Poetto beach in Cagliari (Sardinia, Italy) acquired from the new-generation WorldView-2 sensor. Launched in October 2009, the WorldView-2 sensor provides, among others, one (named Coastal) that was designed specifically for this kind of analysis; we chose to use the Coastal band in place of the Blue one when applying the model. The images (a stereoscopic pair) were acquired on June 17, 2011. The 5419 scene was pre-processed in order to separate the sea bottom classes. This class was then georeferenced to overlap on the 5318 scene. A traditional bathymetric survey was performed, up to $1,50 \mathrm{~m}$, planned and carried out in order to calibrate the model. For each scene, 10 calibration areas were selected, and for each of them a digital model of the sea bottom was generated. Precision and accuracy of the method were evaluated by analyzing the results extracted from the stereo-pairs and by examining the correlation between the surveyed depth values and the calculated ones, between the different models calculated from the same scene using different calibration areas, and between the models obtained from the two images.
\end{abstract}

\section{INTRODUCTION}

Since 1984, launch date of the Landsat 5 satellite, whose imagery was used for the first bathymetric mapping from satellite images, the technology has advanced in strides. In the last decade, the construction of high resolution sensors such as Ikonos and Quickbird allowed for ever more accurate analysis. Still, to date it's not yet possible to evaluate the precision of the model, but only to estimate the achieved accuracy by comparing the digital models extracted from the imagery with actual bathymetric surveys.

The technique for extracting bathymetric information from satellite imagery is becoming widespread, to the point that the WorldView 2 satellite sensor was designed with a dedicated band named "Coastal". One method for obtaining the precision of the procedure is comparing the results from independed images acquired at the same time. The fact that WorldView2 can produce stereo pairs where the component scenes are acquired in a short time interval thus makes possible to evaluate the precision of the results.

For the purposes of this research it was chosen as a test area the Poetto littoral. Located on the southern coast of the island of Sardinia (Italy), the Poetto is the beach of the city of Cagliari, whose urban area surrounds it. Its geographic position has determined its history: it was always subject to erosion phenomena, mostly of anthropic origin, and for this reason in 2002 it underwent a beach nourishment intervention with sand collected from the sea.

The evaluation of accuracy was performed by comparing the depth values extracted from each scene, between the different scenes and with the bathymetric survey.

In each scene, 10 different deep water areas of 50x50 pixels were selected and used to calibrate the model. The distribution of the calibration areas in the two scenes is shown in Figure 1 and Figure 2.

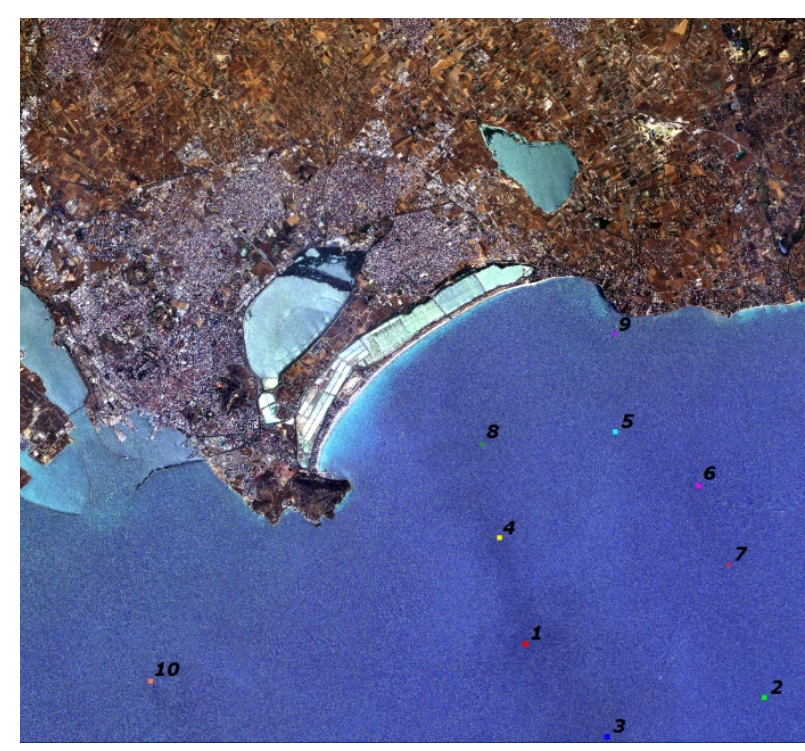

Figure 1. Distribution of the Areas of calibration in the 5318 scene 


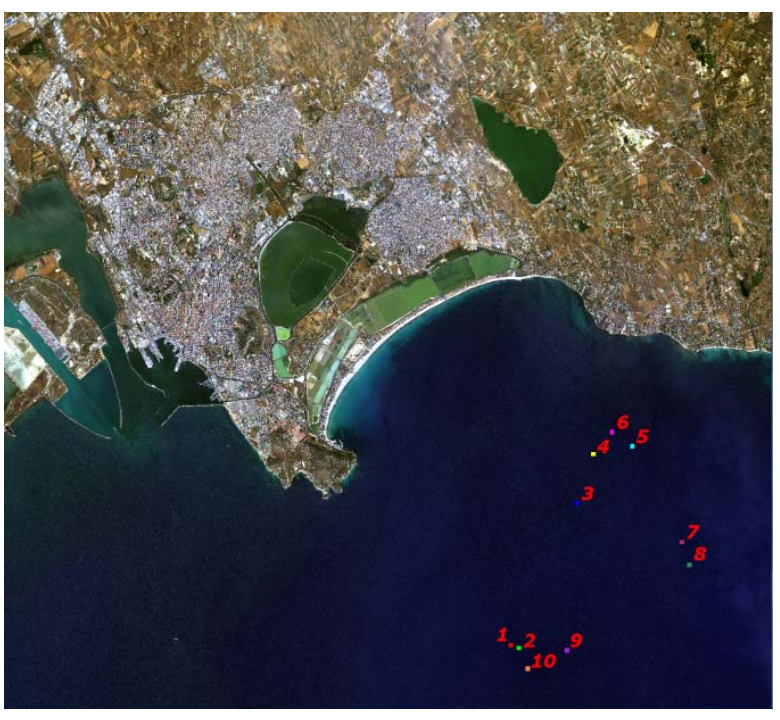

Figure 2. Distribution of the Areas of calibration in the 5419 scene

In the following we will describe the main characteristics of the two scenes, the applied method, and the results.

\section{SCENE DESCRIPTION}

\subsection{Configuration of the stereo pair}

The geometry of the stereo pair was reconstructed by using the information contained in the .STE file accompanying the images. In this file the convergence geometry of the stereoscopic images is described by three angles: convergence angle, asymmetry angle, and bisector elevation angle (BIE). These measure the geometric relationships between two rays that intersect in a point on the ground which is common to the two images, and for this reason are called homologous rays. Two homologous rays define a plane, called convergence plane. The convergence angle is the angle two homologous rays form on the convergence plane; the asymmetry angle is the angle between the projection of the vertical of the point on the convergence plane, and the bisector of the convergence angle; lastly, the BIE is the angle between the bisector and its projection on the horizontal plane (Figure 3). The most important among the three angles is the convergence angle, whose value should vary between $30^{\circ}$ and $60^{\circ}$. It is better to have an asymmetrical acquisition, because this allows to recognize the features on the ground with better accuracy, but the asymmetry angle must remain below $20^{\circ}$. The BIE angle determines the amount of parallax which will appear in the vertical direction after alignment; for this reason it should be between $60^{\circ}$ and $90^{\circ}$ (ISD).

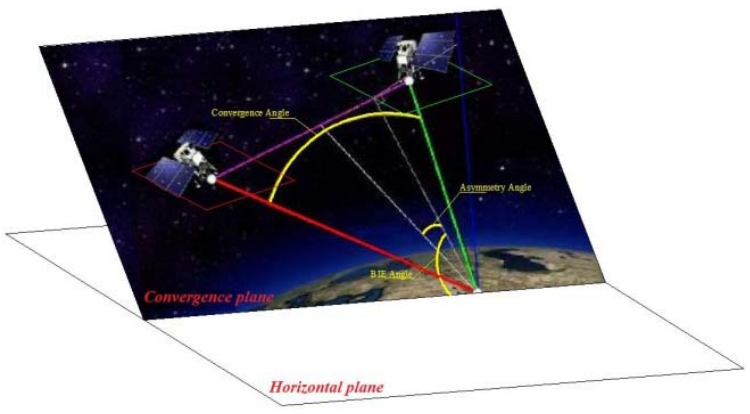

Figure 3. Stereo geometry angles
On June 17 2011, the WorldView2 level 1B stereo pair was acquired over the study area. The area covered by the images contains roughly $100 \mathrm{Km}^{2}$ and is comprised between $9^{\circ} 3^{\prime}$ $30,23^{\prime \prime}$ ' and $9^{\circ} 17^{\prime}$ 57,23' ' in longitude, $39^{\circ} 17^{\prime}$ '57,23” and $39^{\circ}$ 08' 11" in latitude. The characteristics of the two images, both acquires with the sensor in "forward" position, are summarized in Table 1. For the sake of simplicity, the images have been renamed according to the acquisition time: 5318 for the first and 5419 for the second.

\begin{tabular}{l|l|l|}
\cline { 2 - 3 } \multicolumn{1}{c|}{ Parameters } & Image 5318 & Image 5419 \\
\hline Acquisition date & 2011 June 17 & 2011 June 17 \\
\hline Local time & $10: 53: 18$ & $10: 54: 19$ \\
\hline View Zenith & 57.1 & 61.7 \\
\hline View Azimuth & 325.6 & 264.5 \\
\hline Pixel size & 2.394 & 2.220 \\
\hline Sun Zenith angle & 73.1 & 73.2 \\
\hline Sun Azimuth angle & 155.0 & 155.8 \\
\hline Bits per pixel & 16 & $\mathbf{1 6}$ \\
\hline
\end{tabular}

Table 1: Characteristic of the WorldView2 stereo pairs images

The three angles defining the geometry of the stereo pair are reported in the following table:

\begin{tabular}{l|c|}
\multicolumn{1}{c|}{ Angles } & Stereo pair 5318_5419 \\
\hline $\begin{array}{l}\text { Convergence } \\
\text { (beginning - ending) }\end{array}$ & $30.25-30.25$ \\
\hline $\begin{array}{l}\text { Asymmetry } \\
\text { (beginning - ending) }\end{array}$ & $5.09-5.59$ \\
\hline $\begin{array}{l}\text { BIE } \\
\text { (beginning - ending) }\end{array}$ & $63.14-62.67$ \\
\hline
\end{tabular}

Table 2: Angles defining the stereo pair

The geometric configuration of the acquisition is slightly out of the limits described above, both for the convergence and BIE angles, whereas the asymmetry angle is acceptable. The stereo pair also has a $93.3 \%$ overlap.

The .EPH file, which is also part of the image metadata, contains the geocentric coordinates of the points of the orbit and the corresponding accuracies, sampled at constant intervals of 0.2 seconds. The Figure 4 shows the ground projections of the satellites' paths as reconstructed from this file.

This configuration has produced two images of different qualities: while the 5419 image can be considered radiometrically suitable for the purposes of our work, the same cannot be said for the 5318 image. In fact, the latter was acquired in the worst conditions for bathymetric usage, and can almost be considered as a worst-case scenario. 


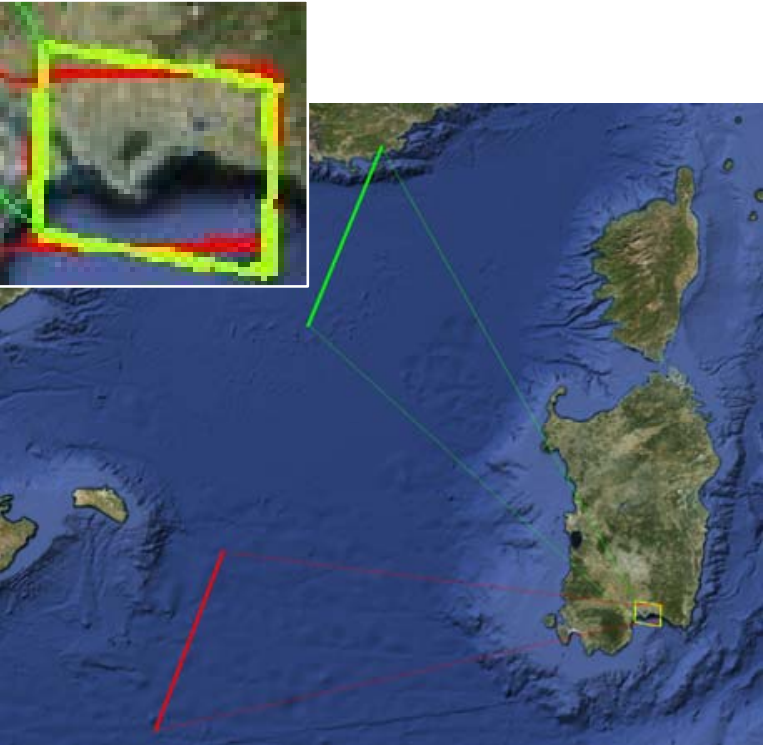

Figure 4. Ground projection of the orbits

\section{DEPTH EXTRACTION}

In order to extract the depth information from the imagery we used the Jupp method as described in Green et al. (2000). The algorithm was implemented by the authors in IDL language and integrated in the ENVI software. The 5419 image was pre processed according to the procedure described in Deidda et al (2012). This procedure divides the image in classes each corresponding to different homogeneous bottom type. Among the classes thus identified, we selected the one corresponding to the sand bottom. This class was represented as a ROI (region of interest) in the ENVI software. We used a coordinate transformation to transport the sand class from the 5419 to the 5318 image, avoiding this way to change the radiance values of the pixels due to georeference interpolation. A traditional bathymetric survey is necessary for the calibrate the method. The DOP zones calculated for the sand bottom class, being parallel to the coastline, were crossed with transverse survey lines, separated about $20 \mathrm{~m}$ from each other. The first band, up to a depth of about $1.50 \mathrm{~m}$, was surveyed with GPS equipment in RTK mode, by two operators who walked along the survey lines. The Jupp model was applied 10 times on each image, once for each selected calibration area. However, not all calibration areas produced valid depth results, and thus some were discarded. In particular, for the 5419 image, the calibration area 1 was discarded because the produced values were extrapolated rather than interpolated; and areas 4, 5 and 8 which produced a very low number of depth values. For the same reason the areas 2, 5 and 9 for the image 5318 were discarded. Areas 6 and 10 were not used because they produced DOP zones which did not overlap the NRTK survey, which covered only part of the littoral. In Figure 5 the extension of the survey is shown in red, and the position of the depth values produced from the 5419 image (using the calibration area 7) in green.In order to distinguish between the depth model obtained by direct survey and the one calculated with the Jupp method for each calibration area, from now on the latter will be referred to as Digital Sea Bottom Model (DSBM).

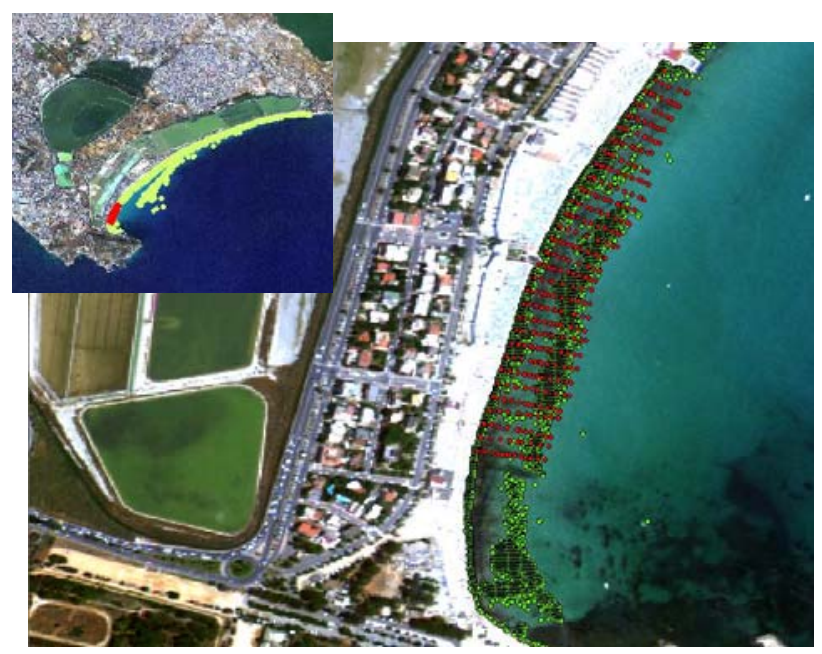

Figure 5. GPS survey (red) and DSBM (green)

\section{ANALYSIS}

Our bathymetry extraction software has produced 6 DSBMs for the image 5419 and 7 for the 5318, each corresponding to a different calibration area (see Figure 1and Figure 2). A direct comparison of the models is not feasible because, due the different calibrations, the points where depth is estimated are not the same (different DOP zones). The strategy used for comparison was thus to spatially intersect the models and limit the comparison to the common areas. The comparison with the NRTK survey of the bottom, which preceded the one between the DSBMs, also required the choice of a criterion to match the points to be compared. In this case, the comparison was made between the surveyed depth and the closest point of the extracted model, up to a distance of one half pixel (1.2 $\mathrm{m}$ on the terrain).

\subsection{Image 5419}

\begin{tabular}{rcr}
\hline $\begin{array}{c}\text { Calibration } \\
\text { area }\end{array}$ & \multicolumn{1}{c}{$\begin{array}{c}\text { Average } \\
(\mathrm{m})\end{array}$} & \multicolumn{1}{c}{$\begin{array}{c}\text { Standard } \\
\text { deviation }(\mathrm{m})\end{array}$} \\
\hline 2 & 0.25 & 0.21 \\
3 & 0.30 & 0.20 \\
6 & 0.21 & 0.20 \\
\hline 7 & 0.21 & 0.19 \\
\hline $\mathbf{9}$ & $\mathbf{0 . 3 9}$ & $\mathbf{0 . 2 2}$ \\
\hline $\mathbf{1 0}$ & $\mathbf{0 . 4 6}$ & $\mathbf{0 . 2 6}$ \\
\hline
\end{tabular}

Table 3: Averages and standard deviations of the differences between the points of the DSBM and those of the NRTK survey for the seven calibration areas of the 5419 image.

Calibration areas 9 and 10 were discarded because the average differences are too high. 


\begin{tabular}{|c|c|c|c|c|c|c|c|c|c|c|}
\hline \multirow{2}{*}{ 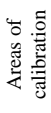 } & \multicolumn{10}{|c|}{ Difference $(\mathrm{m})<$} \\
\hline & 0.1 & 0.2 & 0.3 & 0.4 & 0.5 & 0.6 & 0.7 & 0.8 & 0.9 & 1.0 \\
\hline $2-3$ & $35 \%$ & $46 \%$ & $49 \%$ & $51 \%$ & $\begin{array}{l}54 \\
\%\end{array}$ & $58 \%$ & $64 \%$ & $\begin{array}{l}72 \\
\%\end{array}$ & $\begin{array}{l}81 \\
\%\end{array}$ & $92 \%$ \\
\hline $2-6$ & $38 \%$ & $51 \%$ & $56 \%$ & $58 \%$ & $\begin{array}{l}61 \\
\%\end{array}$ & $64 \%$ & $69 \%$ & $\begin{array}{l}75 \\
\%\end{array}$ & $\begin{array}{l}83 \\
\%\end{array}$ & $93 \%$ \\
\hline $2-7$ & $68 \%$ & $89 \%$ & $96 \%$ & $98 \%$ & $\begin{array}{l}99 \\
\%\end{array}$ & $99 \%$ & $99 \%$ & $\begin{array}{l}99 \\
\%\end{array}$ & $\begin{array}{l}99 \\
\%\end{array}$ & $\begin{array}{c}100 \\
\%\end{array}$ \\
\hline 3-6 & $62 \%$ & $86 \%$ & $95 \%$ & $98 \%$ & $\begin{array}{l}99 \\
\%\end{array}$ & $\begin{array}{c}100 \\
\%\end{array}$ & $\begin{array}{c}100 \\
\%\end{array}$ & $\begin{array}{c}100 \\
\%\end{array}$ & $\begin{array}{c}100 \\
\%\end{array}$ & $\begin{array}{c}100 \\
\%\end{array}$ \\
\hline 3-7 & $75 \%$ & $94 \%$ & $98 \%$ & $99 \%$ & $\begin{array}{l}10 \\
\%\end{array}$ & $\begin{array}{c}100 \\
\%\end{array}$ & $\begin{array}{c}100 \\
\%\end{array}$ & $\begin{array}{c}100 \\
\%\end{array}$ & $\begin{array}{c}100 \\
\%\end{array}$ & $\begin{array}{c}100 \\
\%\end{array}$ \\
\hline 6-7 & $86 \%$ & $97 \%$ & $99 \%$ & $\begin{array}{c}100 \\
\%\end{array}$ & $\begin{array}{c}100 \\
\%\end{array}$ & $\begin{array}{c}100 \\
\%\end{array}$ & $\begin{array}{c}100 \\
\%\end{array}$ & $\begin{array}{c}100 \\
\%\end{array}$ & $\begin{array}{c}100 \\
\%\end{array}$ & $\begin{array}{c}100 \\
\%\end{array}$ \\
\hline
\end{tabular}

Table 4: Percentiles of the differences between the remaining calibration areas of image 5419 which are lower than the thresholds indicated by the column headers

The calibration area 2 shows a very low consistency with the others (lower than $50 \%$ at the $20 \mathrm{~cm}$ threshold), thus it was discarded.

Calibration areas 3, 6 and 7, on the other hand, are consistent both with each other and with the NRTK survey. The DSBMs obtained from them can thus be considered valid and equivalent.

\subsection{Image 5318}

The different calibration areas for the image 5318 were processed in the same way.

\begin{tabular}{rcr}
\hline $\begin{array}{c}\text { Area of } \\
\text { calibration }\end{array}$ & $\begin{array}{c}\text { Average } \\
(\mathrm{m})\end{array}$ & \multicolumn{1}{c}{$\begin{array}{c}\text { Standard } \\
\text { deviation }(\mathrm{m})\end{array}$} \\
\hline 1 & 0.00 & 0.38 \\
3 & 0.27 & 0.34 \\
4 & 0.27 & 0.34 \\
7 & $\mathbf{0 . 5 0}$ & $\mathbf{0 . 2 9}$ \\
\hline & 0.13 & 0.47 \\
\hline
\end{tabular}

Table 5: Averages and standard deviations of the differences between the points of the DSBM and those of the NRTK survey for the calibration areas of the 5318 image

The calibration areas 6 and 10 produced DOPs that did not overlap with the NRTK survey, thus they were discarded. Area 7 was also discarded due to excessive average differences with the NRTK.

The comparison between the remaining DSBMs proceeded with the same methods as for image 5419. The results are shown in the following

Table 6.

All the calibration areas shown internal consistency at the $20 \mathrm{~cm}$ threshold. The DSBMs produced from all of them are thus considered valid and equivalent. Finally, with the same method the valid DSBMs obtained from the 5419 image were compared with the ones from the 5318 one.

The table 7 shows no percentiles over $50 \%$ for thresholds under $0.6 \mathrm{~m}$. Thus, this appears to be the limit for the precision of the method.

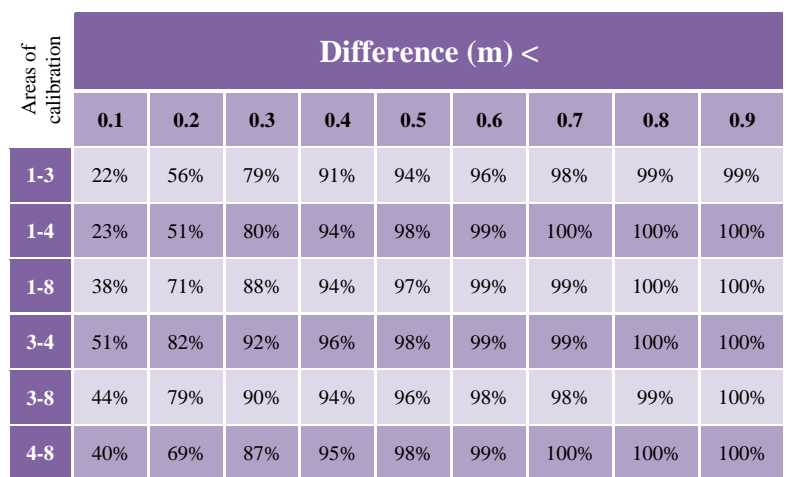

Table 6: Percentiles of the differences between the remaining calibration areas of image 5318 that are lower than the thresholds indicated by the column headers

\section{CONCLUSION}

Based on the comparisons made here we can say that, despite the two images being different in geometry and quality, the results coincide to a precision of about $0.6 \mathrm{~m}$. This first approximation will allow us to choose the quality parameters of the bathymetric surveys which will be used to calibrate the method. For the immediate future, in fact, we are planning a bathymetric survey of a wider area, which will allow us to create the DOP zones for the other bands of the sensor, and especially for the Coastal band.

\begin{tabular}{|c|c|c|c|c|c|c|c|c|c|c|}
\hline \multirow{2}{*}{ 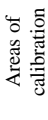 } & \multicolumn{10}{|c|}{ Difference $(\mathrm{m})<$} \\
\hline & 0.1 & 0.2 & 0.3 & 0.4 & 0.5 & 0.6 & 0.7 & 0.8 & 0.9 & 1.0 \\
\hline 3-1 & $9 \%$ & $24 \%$ & $37 \%$ & $46 \%$ & $53 \%$ & $60 \%$ & $65 \%$ & $71 \%$ & $77 \%$ & $85 \%$ \\
\hline 3-3 & $21 \%$ & $37 \%$ & $47 \%$ & $54 \%$ & $61 \%$ & $66 \%$ & $73 \%$ & $80 \%$ & $88 \%$ & $94 \%$ \\
\hline 3-4 & $21 \%$ & $37 \%$ & $47 \%$ & $55 \%$ & $60 \%$ & $66 \%$ & $73 \%$ & $81 \%$ & $89 \%$ & $95 \%$ \\
\hline 3-8 & $15 \%$ & $31 \%$ & $42 \%$ & $50 \%$ & $57 \%$ & $64 \%$ & $70 \%$ & $76 \%$ & $84 \%$ & $93 \%$ \\
\hline 6-1 & $2 \%$ & $4 \%$ & $14 \%$ & $30 \%$ & $41 \%$ & $50 \%$ & $58 \%$ & $65 \%$ & $72 \%$ & $83 \%$ \\
\hline 6-3 & $10 \%$ & $23 \%$ & $36 \%$ & $46 \%$ & $54 \%$ & $61 \%$ & $69 \%$ & $78 \%$ & $87 \%$ & $93 \%$ \\
\hline 6-4 & $13 \%$ & $25 \%$ & $36 \%$ & $45 \%$ & $53 \%$ & $60 \%$ & $68 \%$ & $78 \%$ & $87 \%$ & $95 \%$ \\
\hline 6-8 & $6 \%$ & $14 \%$ & $26 \%$ & $38 \%$ & $48 \%$ & $55 \%$ & $63 \%$ & $71 \%$ & $81 \%$ & $91 \%$ \\
\hline $7-1$ & $2 \%$ & $5 \%$ & $18 \%$ & $38 \%$ & $52 \%$ & $62 \%$ & $69 \%$ & $75 \%$ & $80 \%$ & $90 \%$ \\
\hline $7-3$ & $14 \%$ & $31 \%$ & $46 \%$ & $59 \%$ & $68 \%$ & $75 \%$ & $80 \%$ & $87 \%$ & $94 \%$ & $97 \%$ \\
\hline 7-4 & $18 \%$ & $34 \%$ & $47 \%$ & $57 \%$ & $66 \%$ & $72 \%$ & $79 \%$ & $86 \%$ & $93 \%$ & $98 \%$ \\
\hline 7-8 & $9 \%$ & $20 \%$ & $35 \%$ & $50 \%$ & $61 \%$ & $69 \%$ & $75 \%$ & $80 \%$ & $86 \%$ & $94 \%$ \\
\hline
\end{tabular}

Table 7: Percentiles of the differences between the remaining calibration areas of image 5419 and those of image 5318 which are lower than the thresholds indicated by the column headers.

This research was co-financed by the Autonomous Regional Government of Sardinia (Regione Autonoma della Sardegna) with funds from the "PO Sardegna FSE 2007-2013" and the Regional Law 7/2007 "Promotion of scientific research and technological innovation in Sardinia" 
International Archives of the Photogrammetry, Remote Sensing and Spatial Information Sciences, Volume XXXIX-B8, 2012 XXII ISPRS Congress, 25 August - 01 September 2012, Melbourne, Australia

\section{BIBLIOGRAPHY}

Deidda M., Sanna G. 2012. Pre-processing of high resolution satellite images for sea bottom. Italian Journal of Remote Sensing, 44(1), pp. 83-95

Digital Globe. Imagery Support Data (ISD) Documentation. Supplemental information for the product guide http://www.digitalglobe.com/downloads/Imagery_Support_Dat a_Documentation.pdf (11 Jan. 2011).

E. P. Green et al., Remote Sensing for Tropical Coastal Managment, Parigi, UNESCO, 2000

Jupp, D.L.B., 1988, Background and extensions to depth of penetration (DOP) mapping in shallow coastal waters. Proceedings of the Symposium on Remote Sensing of the Coastal Zone, Gold Coast, Queensland, September 1988, IV.2.1-IV.2.19 